MANAGEMENT, ALGEMEEN - BEDRIJFSPROCES, ALGEMEEN - AUTOMATISERING, COMPUTER

\title{
Het millenniumprobleem
}

\author{
Succes- en faalfactoren
}

\section{J. Pasmooij}

\section{Inleiding}

Op het moment dat dit artikel verschijnt resteren nog 15 maanden om het millenniumprobleem op te lossen. Een periode die voor veel organisaties te kort zal blijken om alle problemen voor te zijn. Men zal zich noodgedwongen moeten beperken tot die systemen en processen die essentieel zijn voor het voortbestaan van de organisatie. Een vorm van crisismanagement met als doel risicobeheersing is voor de organisaties die nu nog moeten beginnen het maximaal haalbare.

Het millenniumprobleem wordt gekenmerkt door voortschrijdend inzicht. Toen begin jaren negentig de eerste meer uitgebreide publicaties over het millenniumprobleem verschenen, gingen de meeste mensen er nog van uit dat het slechts een probleem was dat alleen in oude, veelal administratieve systemen voorkwam. Inmiddels is duidelijk dat het probleem wijd verspreid is en in alle, ook de meest recente, systemen kan voorkomen. Met name de afgelopen 2 jaar is duidelijk geworden dat het probleem ook kan optreden in de zogenaamde embedded systemen: programmatuur die in chips of specifiek daartoe ingerichte computersystemen is opgenomen en zorgdraagt voor de aansturing van allerhande

J. Pasmooij RE RA is plaatsvervangend hoofd EDP Audit Pool en (deeltijd) wetenschappelijk hoofddocent aan de postdoctorale edp-auditopleiding van de Erasmus Universiteit De heer Pasmooij is, mede als voorzitter van de NIVRA/ NOVAA/NOREA-werkgroep Millennium, vanaf eind 1996 intensief betrokken bij de aanpak van de millenniumproblematiek. Het artikel is op persoonlijke titel geschreven. processen. Door organisaties uitgevoerde inventarisaties en analyses brachten aan het licht dat meer organisaties dan verwacht voor hun functioneren en dus ook voor de aanpak en oplossing van het millenniumprobleem athankelijk zijn van derden. Deze afhankelijkheid wordt de ketenproblematiek genoemd. Ook de kostenschattingen zijn regelmatig bijgesteld. Werden de kosten in eerste instantie voor Nederland geschat op circa 10 miljard gulden, nu wordt al uitgegaan van circa 20 miljard gulden.

\section{Succes- en faalfactoren}

De aanpak van het probleem is mede gebaseerd op ervaringen van, met name, een aantal grotere organisaties die al een aantal jaren geleden met de oplossing van het probleem zijn gestart. Op grond van hun ervaringen en onderzoek door organisaties als de Gartner Group en PA Consulting Group' kunnen een aantal elementen in de aanpak als succes- en faalfactoren worden aangemerkt. De bevindingen van deze organisaties komen overeen met ervaringen die inmiddels zijn opgedaan met de aanpak van de problematiek binnen de overheid.?

\section{I Een projectmatige anpak}

Het ontbreken van voldoende betrokkenheid van de leiding, duidelijkheid ontrent taken. verantwoordelijkheden, bevoegdheden en mandaat wordt gezien als de belangrijkste tekortkoming in projectorganisaties. Een en ander kan leiden tot onbeheersbaarheid van het project en in het ergste geval competentiestrijd en patstellingen

De belangrijkste succesfactor is de wijze waarop het millenniumproject wordt aangepakt. 
Het managen van een dergelijk organisatiebreed project vereist, ook bij een verregaande decentralisatie van aanpak en uitvoering, een centrale aansturing en coördinatie. Tevens is het noodzakelijk dat de projectverantwoordelijke voldoende bevoegdheden heeft om zo nodig in te kunnen grijpen indien de overeengekomen deadlines niet worden gehaald. Het ontbreken van een adequate sturing houdt het risico in dat op decentraal niveau beslissingen worden genomen en prioriteiten worden gesteld die op gespannen voet kunnen staan met de belangen van de organisatie als geheel. Ook wordt door deskundigen in deze situatie het Nederlandse poldermodel als extra risicofactor gezien omdat in vele gevallen de tijd voor uitgebreid overleg ontbreekt.

Een ander belangrijk punt bij de aanpak van het probleem is een vorm van kwaliteitszorg.

\subsection{Kwaliteitszorg}

Het ontbreken van een goede kwaliteitszorg kan ertoe leiden dat alle inspanningen bij de jaarwisseling naar het jaar 2000 alsnog tevergeefs blijken.

Een vorm van kwaliteitsbeheersing en -bewaking dient bij de aanpak van het millenniumprobleem de betrouwbaarheid van de verstrekte informatie alsmede de kwaliteit van de uitvoering te waarborgen. Betrouwbare informatie is van belang omdat sturing van het project mede op grond van deze informatie plaatsvindt. Het periodiek toetsen van de kwaliteit stelt belanghebbenden in staat inzicht te verkrijgen in de kwaliteit en bij gebleken tekortkomingen tijdig bij te sturen.

Het is niet noodzakelijk dat de projectorganisatie de uitvoering van het millenniumproject en de waarborging van de kwaliteit volledig zelf ter hand neemt. Het is mogelijk dat de projectorganisatie faciliterend is aan de verschillende organisatie-onderdelen, die zelf verantwoordelijk zijn voor de feitelijke uitvoering. In dat geval is het noodzakelijk dat duidelijk is wat van deze organisatie-onderdelen wordt verwacht, waarvoor zij verantwoordelijk zijn en waarop zij zullen worden afgerekend. Kwaliteitstoetsen kunnen worden uitgevoerd door het verantwoordelijke (lijn)management en/of de projectorganisatie zelf of uitbesteed aan een derde onafhankelijke deskundige.
Kwaliteitstoetsen kunnen betrekking hebben op de aanpak en beheersing van het millenniumprobleem (de projectorganisatie), alsmede op de kwaliteit van de individuele werkzaamheden. Een voorwaarde voor het kunnen uitvoeren van kwaliteitstoetsen is concrete afspraken vooraf en de beschikbaarheid van een toereikende (juiste, volledige, actuele, controleerbare) verslaglegging van de uitgevoerde werkzaamheden achteraf.

Dergelijke vastleggingen (registraties) zijn ook noodzakelijk voor het kunnen uitvoeren van toekomstig onderhoud en het zo nodig opstellen van noodscenario's. Ook bij het alsnog onverhoopt optreden van problemen is het noodzakelijk over actuele informatie omtrent het desbetreffende object te kunnen beschikken. Het testen van de aangepaste of vervangen systemen door een onafhankelijk organisatie-onderdeel kan ook als een soort kwaliteitstoets worden gezien. Men dient zich echter te bedenken dat deze 'toets' veel aan het eind van het traject zal plaatsvinden, hetgeen kan betekenen dat het oplossen van nog bestaande problemen een aanzienlijke inspanning in tijd en menskracht kan vragen. Een vorm van kwaliteitszorg moet ertoe bijdragen dat millenniumbestendige objecten worden opgeleverd.

Reeds in organisaties functionerende kwaliteitsmanagers kunnen bij de opzet en invulling van de kwaliteitszorg binnen millenniumprojecten een belangrijke rol spelen.

\subsection{Millenniumbestendigheid}

Organisaties hanteren niet altijd dezelfde definitie voor millenniumbestendigheid. Om die reden is het van belang in alle gevallen na te gaan wat hieronder wordt verstaan.

Het vaststellen of een object (product of proces) millenniumbestendig is, is in de praktijk niet eenvoudig. Het vereist naast kennis van het bedrijfsproces waarin het object een rol speelt, veelal specifieke technische kennis. Een uitspraak omtrent de millenniumbestendigheid van een object geeft echter nog geen enkele zekerheid dat dit object in combinatie met andere producten/ processen nog goed zal blijven functioneren. De onderlinge beïnvloeding of afhankelijkheid wordt ook wel het keteneffect genoemd.

Zekerheid hieromtrent kan alleen worden verkregen door de producten/processen in samenhang met elkaar te testen. Zie in dit verband mede paragraaf 2.8 . 


\subsection{Garanties van leveranciers}

Ervaringen wijzen uit dat veel organisaties onvoldoende duidelijkheid scheppen omtrent de millenniumbestendigheid van hun producten of diensten. Indien door leveranciers garantieverklaringen zijn afgegeven is het niet verstandig hier zonder meer op af te gaan. Nagegaan zal moeten worden of de leverancier zijn verplichtingen kan nakomen of al is nagekomen en wat zijn garantieverklaring feitelijk inhoudt.

Daarvoor dient antwoord te worden verkregen op de volgende vragen:

welke definitie voor millenniumbestendigheid hanteert de leverancier?

waarop heeft de garantieverklaring betrekking: zijn er voorwaarden of uitsluitingen? hoe staat de leverancier bekend?

welke ervaringen zijn in het verleden met deze leverancier opgedaan?

wanneer zal de millenniumbestendige versie worden geleverd? Bij hun afweging dienen organisaties rekening te houden met de periode dat zij op een millenniumbestendige versie willen of kunnen wachten zonder de eigen planning in gevaar te brengen. welke methode (oplossingsrichting) heeft de leverancier gekozen om zijn pakket millenniumbestendig te maken? Er zijn een aantal oplossingsrichtingen mogelijk die echter onderling kunnen conflicteren. Alhoewel het uitbreiden van de datumvelden voor de jaartallen tot vier posities (expansie) het meest voor de hand ligt kiezen sommige leveranciers echter voor de window-techniek (interpretatie). Bij gebruik van deze techniek wordt de binnen een systeem gehanteerde notatie van jaartallen (twee posities) niet aangepast. Door middel van extra programmatuur wordt gerealiseerd dat de jaartallen die binnen een vooraf bepaalde range vallen, door het systeem worden beschouwd als zijnde van de twintigste of de eenentwintigste eeuw. Deze techniek biedt echter maar een tijdelijke oplossing.

hoe groot is het aantal huidige en verwachte gebruikers van een millenniumbestendige versie'? Indien het aantal huidige en toekomstige gebruikers zeer beperkt zal zijn is het niet denkbeeldig dat een leverancier het alsnog laat afweten.

op welke wijze, met welke intensiteit en onder welke omstandigheden is de millenniumbestendige versie getest (welke versie, relatie met andere systemen)? Afhankelijk van de zekerheid die een leverancier verstrekt is het veelal aan te bevelen zelfstandig het correct functioneren van een object vast te stellen door middel van het uitvoeren van een aantal tests.

Organisaties die zelf producten en/ol diensten leveren zullen er zich op moeten voorbereiden dat afnemers aan hen vergelijkbare eisen zullen stellen. Zie in dit verband ook paragraaf 2.6.

\subsection{Embedded software-systemen}

Embedded software is programmatuur, veelal vastgelegd in computerchips of speciaal daarvoor bestemde computers (vaak PC's), met een vooraf bepaalde en vastgelegde functionaliteit. Deze programmatuur wordt door bedrijven gemaakt ten behoeve van de aansturing van allerlei apparaten en processen, zoals klokthermostaten, medische apparatuur, klimaatsystemen, maar ook systemen voor het beheersen en bewaken van het lucht- en wegverkeer of het aansturen van bedrijfsprocessen

Gebruikers kunnen vaak door het gebruik van toetsen de programma's instellen en activeren. Het wijzigen van de functionaliteit is echter veelal niet mogelijk daar deze is voorgeprogrammeerd. Het aantal computerchips dat op deze wijze wordt gefabriceerd en geïmplementeerd in verschillende producten beloopt in de miljarden. Volgens de Gartner Group is het mogelijk dat de afgelopen tien jaar zo'n slordige 30 miljard chips zijn geproduceerd, waarvan tussen de 50 en 300 miljoen naar verwachting behept zijn met een datumprobleem.

Om na te kunnen gaan of in een apparaat of systeem sprake is van een - mogelijk problematisch - embedded systeem is nader overleg met de leverancier noodzakelijk.

Hierbij kan zich het probleem voordoen dat:

- deze inmiddels niet meer bekend is;

niet meer bekend is wie het apparaat/systeem destijds heeft geleverd;

de leverancier de chip destijds bij derden heeft betrokken en niet op de hoogte is van de volledige functionaliteit of het gebruik van datumvelden.

Ingeval niet duidelijk is of het embedded systeem een millenniumprobleem heeft, zal de 
verantwoordelijke - afhankelijk van het belang van het systeem en/of de eventuele schade bij uitval - moeten besluiten niets te doen, het systeem te vervangen of buiten gebruik te stellen.

Het zelfstandig beproeven van een dergelijk systeem door het verzetten van de systeemdatum is niet zonder gevaar omdat het mogelijk is dat het systeem, na het uitvoeren van de proef, door blokkering niet meer kan worden teruggebracht in de huidige situatie of niet (betrouwbaar) meer functioneert. Ook is het mogelijk dat door het vooruitzetten van de datum licentietermijnen worden overschreden, hetgeen er ook toe kan leiden dat het systeem niet meer functioneert.

De embedded software-systemen worden op dit moment, naast de ketenproblematiek, gezien als de grootste risicofactor.

\subsection{Ketenproblematiek}

Onder ketenproblematiek wordt de afhankelijkheid van derden verstaan die bestaat bij het normale bedrijfsgebeuren, met inbegrip van de aanpak en oplossing van het millenniumprobleem. Problemen kunnen ontstaan door koppelingen met systemen van derden, waarin het probleem niet (tijdig) is opgelost. Ook is het mogelijk dat belangrijke relaties (bijvoorbeeld toeleveranciers en afnemers) door een onvoldoende aanpak niet aan hun verplichtingen voldoen, of in het uiterste geval zelfs failliet gaan. Een dergelijke situatie kan zich ook voordoen indien (delen van) beheer, onderhoud en/of gegevensverwerking zijn uitbesteed aan of ondergebracht bij derden.

Het kan eveneens voorkomen dat organisaties voor de (tijdige) oplossing van hun problemen afhankelijk zijn van derden. Hierbij kan worden gedacht aan leveranciers die millenniumbestendige apparatuur of programmatuur moeten leveren die voor uw bedrijfsproces van essentieel belang is.

De ketenproblematiek speelt ook een rol bij het kiezen van een oplossing. Zo komt het voor dat organisaties die in een zelfde bedrijfstak of branche werkzaam zijn en vaak van dezelfde systemen gebruikmaken in overleg voor één oplossing kiezen

Teneinde continuïteitsrisico's te verkleinen is het wenselijk tijdig bij afnemers, leveranciers of dienstverleners na te gaan in hoeverre zij (tijdig) millenniumbestendig zijn.

Organisaties moeten er rekening mee houden dat afnemers, die voor hun bedrijfsproces afhankelijk zijn van bepaalde producten of diensten van deze toeleveranciers zullen eisen dat zij voor een bepaalde datum aantonen dat zij millenniumbestendig zijn. Het niet kunnen aantonen van millenniumbestendigheid kan aanleiding zijn het leveringscontract op te zeggen.

Om te voorkomen dat vitale processen in de Nederlandse samenleving stil vallen volgt het kabinet de ontwikkelingen bij organisaties die verantwoordelijk zijn voor de vitale processen (onder andere energie, water, voeding, communicatie, gezondheidszorg) op de voet.

In april 1998 heeft de regering aangegeven niet te zullen aarzelen in te grijpen bij vitale sectoren van de Nederlandse economie als het millenniumprobleem niet in hoog tempo wordt aangepakt. ${ }^{3}$

Onnodige risico's kunnen worden voorkomen door tijdig overleg, het maken van afspraken, het in voorkomende gevallen gemeenschappelijk testen van systemen en het ontwikkelen van noodscenario's. Zie in dit verband ook paragraaf 2.9 .

\subsection{Aansprakelijkheid}

Organisaties moeten er rekening mee houden dat de millenniumproblematiek juridische gevolgen kan hebben voor geleverde of nog te leveren producten en/of diensten.

Dit speelt vooral bij organisaties die softwareproducten en/of hardware(componenten) met embedded software leveren. Het is dikwijls onduidelijk wie de kosten voor de aanpassing of vervanging moet dragen. Het is niet uitgesloten dat deze kosten ten laste van de leverancier en/of de producent kunnen komen. Tevens moet rekening worden gehouden met het risico van schadeclaims indien geleverde software en/of hardware(componenten) niet meer of onbetrouwbaar werkt vóór, tijdens en na de eeuwwisseling. Ook bestaat de mogelijkheid dat bestuurders van organisaties die geen of niet tijdig adequate maatregelen hebben getroffen aansprakelijk zullen of kunnen worden gesteld (bestuurdersaansprakelijkheid).

Op verzoek van het kabinet heeft de landsad- 
vocaat nader onderzoek naar deze problematiek gedaan. Uit het advies van de landsadvocaat dat als bijlage bij de brief d.d. 6 oktober 1997 van het kabinet aan de Tweede Kamer is gevoegd (Tweede Kamer, vergaderjaar 1997-1998, 25 6743, nr. 1. bijlage 2) komt naar voren dat het niet mogelijk is om in algemene zin uitspraken te doen in welke situatie een leverancier aansprakelijk kan worden gesteld. Wel kan in algemene zin worden opgemerkt dat een tekstuele uitleg van een contract niet altijd bindend is. Situationele overwegingen blijken evenzeer van belang. Hierbij kan onder meer worden gedacht aan de leeftijd van een systeem, de redelijkheid van een claim, de verhouding van de oorspronkelijke contractprijs en de schade en het land van vestiging van een leverancier.

Een tweede punt in het advies betreft de positie van de consument/burger. In het geval een burger letselschade of financiële schade lijdt ten gevolge van het niet millenniumbestendig zijn van een bepaald systeem, kan deze een producent of leverancier aansprakelijk stellen. Voorts blijkt uit het advies van de landsadvocaat dat het naar alle waarschijnlijkheid niet mogelijk is tijdig duidelijkheid te creëren over de aansprakelijkheid door middel van noodwetgeving. De vereiste wetgevingsprocedure loopt naar verwachting door tot na 2000 .

De omstandigheid dat het via de weg van een juridische procedure zeker een aantal jaren kan duren voordat duidelijk is wie waarvoor kan worden aangesproken, heeft het Millennium Platform (zie voor een nadere toelichting punt 4) ertoe gebracht alle organisaties het scenario 'eerst maken dan knokken' te adviseren. Om nu te voorkomen dat de aanpak van de millenniumproblematiek gefrustreerd wordt door juridische procedures adviseert het Millennium Platform alle organisaties wel hun uitgangspositie duidelijk vast te leggen maar in eerste plaats door overleg en samenwerking tot oplossingen te komen.

Het advies van het Millennium Platform heeft tevens tot voordeel dat op het moment dat daadwerkelijk tot het instellen van claims en/of procedures besloten moet worden, de algemene vragen rond de al-dan-geen aansprakelijkheid meer uitgekristalliseerd zullen zijn dan nu het geval is, zodat te zijner tijd een meer gefundeerde afweging kan worden gemaakt over de vraag, of en zo ja; wat, en met welke kans van slagen, er geclaimd kan worden.

Uit onderzoek van verschillende deskundigen komt naar voren dat ondernemers die de aanpak van het millenniumprobleem op zijn beloop laten hun recht verspelen op een eventuele schadevergoeding in de toekomst. Ook blijkt dat bedrijven een 'waarschuwingsplicht' hebben. Zij moeten doen wat redelijkerwijs mogelijk is om eventuele schades te voorkomen.

Afhankelijk van de aard van bedrijfsprocessen kan het niet tijdig presteren er ook toe leiden dat niet (tijdig) aan wettelijke verplichtingen kan worden voldaan. Hierbij kan worden gedacht aan het voldoen aan wettelijke termijnen.

\subsection{Testen}

De praktijktest bij VSB Bank toont aan hoe belangrijk het testen van systemen ist.

Tijdens een praktijktest bleek een deel van de systemen toch onverwachte storingen te vertonen. Ook bij andere organisaties blijkt bij het testen dat niet alle problemen zijn opgelost of in sommige gevallen zelfs niet voorzien. Om die reden is het uiterst onverstandig om het testen achterwege te laten.

De aangepaste of (nieuw) aangeschafte of vervangen objecten zullen moeten worden getest op het correct functioneren voor, tijdens en na de overgang van het jaar 2000 .

Met betrekking tot het testen zal een omgeving moeten worden gecreëerd, zoals deze in het jaar 2000 zal bestaan. In de test zal moeten worden vastgesteld dat:

de functionaliteit van het object na aanpassing of vervanging (millenniumbestendige versie) niet is gewijzigd. Dit vereist het testen van alle functies (regressietest);

alle wijzigingen juist en volledig zijn doorgevoerd. Hierbij dient rekening te worden gehouden met de gekozen oplossing; het object op cruciale momenten in het bedrijfsproces in relatie tot tijdsmomenten (bijvoorbeeld dagritme, schrikkeljaar) en andere systemen goed blijft functioneren. Dit betekent dat het object - mogelijk in combinatie met andere objecten/systemen - een soort tijdreis moet maken waarbij alle cruciale tijdsmomenten worden getest: 
- de overgang van 1998 naar 1999 (in verband met gebruik ' 99 ');

- de datum 9 september 1999 (in verband met het gebruik van ' 99 ');

- de overgang van 1999 naar 2000;

- 29 februari 2000 (schrikkeljaar);

- 3 januari 2000 (maandag, eerste werkdag);

- de overgang van 29 februari 2000 naar 1 maart 2000 (schrikkeljaar);

- de overgang 30 december 2000 naar 31 december 2000 (schrikkeljaar, het komt voor dat systemen het aantal dagen bijhouden en dan bij 365 dagen toch overgaan naar een nieuw jaar);

- de overgang van 2000 naar 2001;

- de overgang van 28 februari 2001 naar 1 maart 2001;

- een verwerkingsdatum na het jaar 2001.

Voor infrastructuur (besturingsprogrammatuur, databasemanagementsystemen, netwerken, et cetera) betekent een en ander dat zal moeten worden vastgesteld dat alle operationele functies (zoals operating, back-up en recovery, beheer van gegevens, programmatuur, integriteitsbewaking, logging) op alle momenten in de tijd correct functioneren.

Bij het testen worden organisaties geconfronteerd met het feit dat het in de praktijk niet eenvoudig is een testomgeving te realiseren die overeenkomt met de situatie zoals die zich in het jaar 2000 zal voordoen. Problemen waar men tegen aanloopt zijn:

- het binnen een organisatie niet kunnen creëren van een aparte testomgeving;

- het nog niet beschikbaar zijn van alle millenniumbestendige versies van programmatuur, hardware, et cetera;

- het testen van objecten/systemen in relatie tot andere objecten/systemen (van derden);

- het testen van objecten/systemen in relatie tot bedrijfsprocessen (bijvoorbeeld embedded systemen die productieprocessen aansturen);

- het testen van technische infrastructuur.

Met name het testen van objecten/systemen in relatie tot andere objecten/systemen of bedrijfsprocessen en het testen van de technische infrastructuur stuit in de praktijk op nogal wat problemen. Een standaardoplossing is hier niet voorhanden. In overleg met de direct betrokkenen zal moeten worden nagegaan wat in een voorkomende situatie wel en niet kan worden getest zonder lopende processen te verstoren. Hierbij is van belang welke zekerheid leveranciers verstrekken (garantieverklaringen) en welke ervaringen derden inmiddels hebben opgedaan met de desbetreffende objecten.

Ook hangt veel af van de zekerheid die men op andere gronden (analyse, testen van het object) al heeft over de millenniumbestendigheid van het object.

Essentieel is dat bij het testen de gebruikers worden betrokken, die de functionaliteit van het object alsmede de mogelijke omgevingsfactoren kennen. In voorkomende gevallen is het mogelijk testtools in te zetten. In alle gevallen echter is een gestructureerde aanpak, alsmede overleg met alle betrokkenen, gewenst.

\subsection{Noodscenario's}

Het opstellen van noodscenario's wordt door velen gezien als het hebben van onvoldoende vertrouwen in de eigen aanpak. Gezien het feit echter dat, mede als gevolg van de ketenproblematiek, geen volledige zekerheid kan worden verkregen over de millenniumbestendigheid van alle systemen en processen is het zeer wenselijk voor de meest essentiële processen nu al noodscenario's op te stellen.

Deze noodscenario's kunnen onder meer tot doel hebben mogelijke schade te beperken door:

- het kunnen hervatten of herstarten van processen bij onverhoopt uitvallen;

- het, afhankelijk van het proces, over kunnen schakelen op handbediening;

- het (tijdelijk) kunnen voortzetten van het proces zonder ondersteuning van het desbetreffende geautomatiseerde systeem of systemen.

Het op dat moment beschikbaar hebben van de noodzakelijke medewerkers en deskundigen is hiervoor wel noodzakelijk. Een andere mogelijkheid is het instellen van een helpdesk die bij optredende problemen mensen kan informeren en ondersteunen.

Ook kan worden bezien of het megelijk is bepaalde niet noodzakelijke processen gedurende de jaarovergang stil te leggen. In sommige gevallen wordt bij organisaties met een vol 
continu productieproces overwogen om tijdig voor de jaarwisseling naar 2000 het productieproces beheerst stil te leggen om het proces na de jaarwisseling weer beheerst op te kunnen starten.

Van belang is dat nu al wordt nagedacht hoe te handelen (wie doet wat, wanneer, hoe en op basis waarvan) indien zich onverhoopt toch problemen zullen voordoen. Communicatie nu en straks speelt hierbij ook een grote rol.

\section{De bijdrage van accountants en EDP- auditors}

Omdat de problematiek wordt gezien als een maatschappelijk probleem dat vraagt om een gemeenschappelijke aanpak en stellingname, hebben de Besturen van het Koninklijk Nederlands Instituut van Registeraccountants (NIVRA), de Nederlandse Orde van Accountants-Administratieconsulenten (NOvAA) en de Nederlandse Orde van Register EDP-Auditors (NOREA) in het najaar van 1997 een gemeenschappelijke werkgroep Millennium opgericht. Deze werkgroep had en heeft tot taak de gevolgen voor de beroepsuitoefening na te gaan en te bezien welke bijdrage auditors kunnen leveren bij de aanpak en de oplossing van de problematiek.

Naast de concrete adviezen, die in de vorm van 'audit-alerts' medio december 1997 aan alle Accountants-Administratieconsulenten (AA's), Registeraccountants (RA's) en Register EDPauditors (RE's) zijn gezonden, heeft de werkgroep ook een brochure samengesteld 'Het Millenniumprobleem Beheerst?' Deze brochure heeft tot doel de cliënten van accountants en EDP-auditors nader te informeren en waar nodig een handreiking te bieden. Daarnaast biedt de brochure accountants en EDP-auditors ondersteuning bij de aanpak van de millenniumproblematiek.

De bijdrage van accountants en EDP-auditors kan onder meer bestaan uit:

- het bevorderen van de bewustwording;

- het adviseren omtrent en het beoordelen van de projectmatige aanpak (en uitvoering) en het inschakelen van technische deskundigen;

- het verlenen van ondersteuning bij allerhande werkzaamheden die in het kader van het millenniumprobleem door organisaties moeten worden uitgevoerd.
Voor een nadere toelichting wordt verwezen naar de aangegeven millenniumbrochure die bij de aangegeven beroepsorganisaties kan worden aangevraagd.

\section{De Nederlandse aanpak}

Het verstrekken van informatie en het uitwisselen van ervaringen vervult een belangrijke rol bij de aanpak van het millenniumprobleem. Mede om die reden heeft de Nederlandse overheid in het najaar 1997 in samenwerking met het VNONCW en MKB-Nederland het Millennium Platform opgericht. Het platform is opgericht om bedrijven, instellingen en particulieren te waarschuwen voor de ernstige en verstrekkende gevolgen van het millenniumprobleem in hun automatiseringssystemen. Doel is om breed maatschappelijk de aandacht op het onderwerp te vestigen en de bewustwording over de omvang van de problematiek te vergroten. Daarnaast stimuleert het platform het realiseren van oplossingen en het uitwisselen van kennis en ervaringen.

Het platform bestaat uit vertegenwoordigers uit diverse geledingen en heeft een initiërende, stimulerende en sturende functie. Het realiseren van de concrete oplossingen in apparatuur en systemen is de verantwoordelijkheid van elke organisatie, klein of groot, zelf. Het platform heeft gekozen voor een sectorbenadering. Via contacten met vertegenwoordigers van de verschillende sectoren (circa 400) alsmede intermediaire sectoren zoals banken, verzekeringsmaatschappijen, advocaten en accountants, tracht het platform de individuele organisaties tot actie te brengen.

De Nederlandse aanpak is uniek te noemen. In geen enkel land is een dergelijke samenwerking tot stand gebracht. Onderzoek van onder meer PA Consulting Group geeft aan dat Nederland, overeenkomstig de Verenigde Staten, het Verenigd Koninkrijk en een aantal noordelijke landen, de problematiek voortvarend aanpakt. Minder duidelijk is hoe de aanpak verloopt in de ons omringende landen Duitsland en Frankrijk. Nog minder is bekend over landen in het oosten van Europa, Afrika, Azië en Zuid-Amerika. Inmiddels vindt op Europees niveau overleg plaats tussen de landen verenigd in de EU. Financiële instellingen (banken) en de luchtvaart overleggen op mondiaal niveau. 


\section{Nadere informatie}

Daar het millenniumprobleem en de aanpak gekenmerkt worden door voortschrijdend inzicht is het van het grootste belang dat organisaties zich regelmatig op de hoogte stellen van de laatste ontwikkelingen.

Het aantal nationale en internationale organisaties (bedrijven en overheidsinstellingen) dat informatie verstrekt omtrent de millenniumproblematiek, de gehanteerde aanpak, mogelijke oplossingen, et cetera is groot. Deze openheid past bij de aanpak die nationaal en internationaal is gekozen. Het Internet is in dit geval een dankbare bron van informatie. Plannen van aanpak, informatie, ervaringen, checklists, et cetera zijn hier te vinden.

Ook verschijnen er regelmatig speciale publicaties over de millenniumproblematiek, zoals onder meer de gemeenschappelijke millenniumbrochure van het Koninklijk NIVRA, de NOvAA en de NOREA.

Zo heeft het Millennium Platform een informatienummer geopend om vragen te beantwoorden. Dat nummer is: 0800-9992000.

Informatie is ook te verkrijgen op de Internetsite: www.mp2000.nl. Ook wordt er door het Millennium Platform tweemaandelijks een informatieblad 'Millennium Monitor' uitgegeven.

Naast het Millennium Platform zijn door de verschillende branches eigen platforms of informatiepunten ingesteld waar op de branche gerichte informatie wordt verstrekt. Ook kunt u contact opnemen met uw accountant en/of edp-auditor.

\section{I T E R A T U U R}

Brieven aan de voorzitter van de Tweede Kamer der StatenGeneraal inzake de aanpak van het millenniumvraagstuk d.d. 20 juni 1997, 6 oktober 1997, 19 december 1997 en 5 juni 1998.

Compact (1997), Het jaar 2000, Samson Bedrijfsinformatie bv.
Computerrecht (1997), Dossier Millennium, Kluwer.

It \& Recht (1997), Special 2000, Samson Bedrijfsinformatie bv. Gemeenschappelijke brochure NIVRA/NOVAA/NOREA (1998), Het Millenniumprobleem Beheerst?!

Management \& Informatie (1997), Themanummer: 2000 , Samson Bedrijfsinformatie bv.

Millennium Monitor (uitgaven december 1997 en februari en april 1998), TenHagenStam uitgevers.

PA Consulting Group, (1997), Nationaal Millennium Onderzoek, mei 1997, PA Consulting Group.

PA Consulting Group, (1998), Nationaal Millennium Onderzoek, februari 1998, Het Millennium Platform

Pasmooij, J., (1998), De millenniumproblematiek. Het belang van goede kwaliteitszorg als succesfactor bij de aanpak, in: Overheids Management, nummer 4, april 1998, VUGA Uitgeverij B.V.

Een groot aantal artikelen en publicaties in dag- en week- en vakbladen, alsmede Internet.

\section{N O T E N}

1 De PA Consulting Group voert in opdracht van het Millennium Platform periodiek onderzoek uit naar de stand van zaken binnen Nederland. Het laatste rapport geeft een overzicht naar de stand van zaken in februari/maart 1998. Het onderzoek zal worden herhaald per september 1998.

2 Binnen de rijksoverheid is onderzoek gedaan naar de kwaliteit van de projectorganisaties die zijn ingesteld om het millenniumprobleem aan te pakken. In de brief aan de Tweede Kamer d.d. 19 december 1997 is gerapporteerd omtrent de uitkomst van de uitgevoerde toets per 1 december 1997. Uit de rapportage blijkt dat op dat moment slechts twee departementale projectorganisaties als toereikend worden gekwalificeerd. De uitkomsten waren voor het Kabinet aanleiding deze kwaliteitstoets te laten herhalen naar de stand per 1 april 1998 (rapportage per 1 mei 1998). De uitkomsten van dit onderzoek zijn op 5 juni 1998 aan de Tweede Kamer gerapporteerd. Hieruit blijkt dat de kwaliteit van de projectorganisaties is verbeterd. Een aantal departementen scoren echter nog onvoldoende.

3 Artikel in het FD van 3 april 1998.

4 'Champagne tegen de kater. Test VSB Bank bewijst dat 2000-problemen reëel zijn', artikel in: Computable, nr. 39, d.d. 24 juli 1998. 